\title{
Congresso Brasileiro de Enfermagem: sessenta anos de história
}

\author{
The Brazilian Nursing Congress: sixty years of history
}

Congreso Brasileño de Enfermería: sesenta años de historia

\section{Joel Rolim Mancia', Maria Itayra Coelho de Souza Padilha', Flávia Regina Souza Ramos', Fernanda Peixoto Cordova", Nilton Vieira do Amaral"II}

'Universidade Federal de Santa Catarina. Departamento de Enfermagem Programa de Pós-Graduação em Enfermagem. Grupo de Estudos da História do Conhecimento na Enfermagem. Florianópolis, SC

"Centro Universitário Metodista IPA. Porto Alegre, RS

III Universidade Luterana do Brasil. Porto Alegre, RS

Submissão: 22/l l/2008

Aprovação: 03/04/2009

\section{RESUMO}

Este estudo objetivou descrever as Questões ligadas às origens do Congresso Brasileiro de Enfermagem e sua trajetória no período de 1947 a 2007; e discutir a implementação desta estratégia pela Associação Brasileira de Enfermagem (ABEn). É uma investigação histórica com pesQuisa documental. A análise permitiu chegar as seguintes categorias: a origem do Congresso brasileiro de enfermagem e; os congressos como arena política da enfermagem. Concluímos que os Congressos Brasileiros de Enfermagem vêm refletindo a construção da história da Enfermagem brasileira, com vistas a impulsionar a reflexão crítica dos problemas da profissão e investir na produção de conhecimentos, direcionados para a crescente complexidade e Qualidade da prática profissional.

Descritores: História da enfermagem; Sociedades de enfermagem; Congressos.

\section{ABSTRACT}

This study objective is to describe the issues associated to the origin of the Brazilian Nursing Congress and its course between 1947 and 2007; and to discuss the implementation of this strategy by the Brazilian Nursing Association (ABEn). It is a historical survey with documentary research. The documentary analysis allowed reaching the following categories: the origin of the Brazilian Nursing Congress and the congresses as the political nursing arena. We have concluded that the Brazilian Nursing Congresses have reflected the construction of the Brazilian Nursing history, aiming at stimulating the critical consideration on the professional problems and investing in the production of knowledge, addressing the growing complexity and Quality of the professional practice.

Descriptors: History of the Nursing; Nursing societies; Congresses.

\section{RESUMEN}

Este estudio tiene como objetivos describir las cuestiones que se refieren a los orígenes del Congreso Brasileño de Enfermería y su trayectoria en el periodo de 1947 a 2007; y discutir si la Asociación Brasileña de Enfermería (ABEn) debe implantar esta estrategia. Es una investigación histórica con averiguación documental. El análisis documental permitió llegar a las siguientes categorías: el origen del Congreso Brasileño de Enfermería y; los congresos como arena política de la enfermería. Concluimos que los Congresos Brasileños de Enfermería están reflejando la construcción de la historia de la Enfermería brasileña, con el objetivo de impulsar la reflexión crítica de los problemas de la profesión e invertir en la producción de conocimientos, dirigidos a la creciente complejidad y calidad de la práctica profesional.

Descriptores: Historia de la Enfermería; Sociedades de enfermería; Congresos. 


\section{CONSIDERAÇÕES INICIAIS}

A história da enfermagem vem construindo seu conhecimento como um processo dinâmico, Que tende a nascer da prática e a ela se voltar num movimento de busca de níveis crescentes de Qualidade e complexidade. Esse movimento, pontuado por contradições, convergências e decadências, representa a história das/os profissionais, das/os pensadoras/es da enfermagem e da prática de enfermagem. História Que é feita de paixões, de limites e determinações, de interesses e experiências do seu próprio tempo, mas Que também reflete o processo educacional de formação das/ os enfermeiras/os em determinada época e a forma como a prática profissional se constrói. Uma de suas principais metas do processo da construção do conhecimento parece ter sido a de situar a enfermagem no contexto da ciência ${ }^{(1)}$.

Os Congressos Brasileiros de Enfermagem (CBEn), ao refletirem a situação por Que passa a Enfermagem brasileira, vem se constituindo em instância de construção do conhecimento em Enfermagem. Desde o seu início, em 1947, representam uma possibilidade para a discussão dos rumos desta construção e do exercício da profissão, buscando compreendê-los e transformá-los ${ }^{(1)}$.

Nesta perspectiva, este estudo tem como objetivos descrever as Questões ligadas às origens do CBEn e sua trajetória no período de 1947 a 2007; e discutir a implementação desta estratégia pela Associação Brasileira de Enfermagem (ABEn).

\section{METODOLOGIA}

Para este estudo, optamos pela investigação histórica, enQuanto linha metodológica, através da análise documental das atas de reuniões da diretoria da $\mathrm{ABEn}$ relativas ao período, os discursos das presidentes proferidos durante os congressos e publicados nas revistas Anais de Enfermagem e Revista Brasileira de Enfermagem (1947 até 1976) e nos anais do evento (1977 a 2004), bem como em artigos, livros, teses, dissertações, relatórios e documentos do Acervo Fontes da História da Enfermagem do Centro de Estudos e Pesquisas em Enfermagem (CEPEn) da ABEn, no período acima especificado (Criação de Fontes da História da Enfermagem Brasileira). Projeto do CEPEn para organizar um acervo de depoimentos relacionados a história da ABEn. Desenvolvido por leda de Alencar Barreira, teve como objetivo principal gerar fontes primárias de informação em história da Enfermagem, a partir da memória de enfermeiras sobre a ABEn. A análise documental permite obter informações, codificá-las e categorizá-las de forma Quantitativa ou Qualitativa, sendo esta última a de nossa escolha ${ }^{(2)}$. Em um levantamento prévio, realizamos uma leitura exaustiva do material, para obter a codificação das temáticas ou discussões Que eram retomadas ao longo dos anos e Que apresentavam convergências na abordagem temática. Pelo agrupamento destas convergências emergiram as seguintes categorias: a origem do Congresso brasileiro de enfermagem e; os congressos como arena política da enfermagem, as Quais apresentamos, a seguir.

\section{RESULTADOS E DISCUSSÃO}

A origem do Congresso Brasileiro de Enfermagem

A origem do CBEn, pela tradição, se deve a Madre Domineuc
Madre Marie Domineuc (Jeanne Josephine RoQuet) nasceu na França, graduou-se pela Escola de Enfermagem de Paris. Veio para o Brasil em 1935 e no ano de 1938 organizou o serviço de Enfermagem do Hospital São Paulo, onde foi uma das fundadoras da Escola de Enfermagem (atual UNIFESP). Também foi sua iniciativa a criação da UREB União das Religiosas Enfermeiras Brasileiras). Junto com outras lideranças participou da reorganização da ABED na década de 40. Em relação ao Congresso estava convencida de Que somente "um congresso de âmbito nacional de enfermagem poderia unir as enfermeiras e evitar a separação em grupos Que se presenciava", sugeriu, então, Que se fizesse o primeiro $^{(3)}$.

Madre Marie Domineuc, docente da escola de enfermagem do Hospital São Paulo teria sugerido a criação do evento para reunir as enfermeiras, visto Que havia várias escolas no país e muitas enfermeiras formadas e este tipo de atividade era vital para reforçar a unidade da Associação ${ }^{(4)}$. As primeiras tentativas para Que o congresso se realizasse ocorreram no ano de 1945, no entanto, somente em 1946 é que Edith Magalhaes Fraenckel (EMF) convida Zaíra Cintra Vidal para participar do Congresso Que se realizaria em $1947^{(4,5)}$.

Embora a programação científica estivesse sob controle da Associação Brasileira de Enfermagem, por meio das Comissões de Saúde Pública e da Comissão de Educação, Lais Neto dos Reis (LNR) se manifesta criticando a não participação da Escola de Enfermagem Anna Nery (EEAN) na organização do Congresso, já Que havia outras escolas trabalhando para o evento. Esta situação de constrangimento e até de confronto era resultado da disputa pelo poder das duas mais importantes figuras da enfermagem brasileira no período - EMF e $\mathrm{LNR}^{(4,5)}$. As fontes estudadas revelam Que apesar de constar da programação do evento Laís não participou do mesmo, mas enfermeiras católicas se fizeram representar por outras figuras Que não LNR, Que era católica fervorosa, com tradição na defesa da religião. $\mathrm{O}$ Que pode ser inferido é Que a escola padrão não estava representada no Congresso da ABEn e isso foi explicitado por LNR em reunião de diretoria.

Do discurso de Edith Fraenkel no primeiro Congresso, destacamos o seguinte trecho:

“A análise do estado atual da enfermagem no Brasil demonstra dois fatos fundamentais: em primeiro lugar, a desproporção existente entre o número de enfermeiras diplomadas e o número das Que são necessárias para uma boa enfermagem; em segundo lugar o perigo que pode representar, Quer moral Quer profissionalmente, a tendência a sanar essa lacuna, permitindose a formação rápida e incompleta de enfermeiras. A instalação deste Congresso visa exatamente esses dois pontos: há a necessidade de se fomentar a vocação, de se aumentar o número de profissionais, mas é necessário, também, Que se dê um preparo técnico apurado e que se mantenha em dia esse preparo. (...) Para que (os objetivos deste Congresso) realmente se concretizem, é necessário que toda enfermeira tome como norma e use como frase mágica (...) o princípio de que "a união das enfermeiras é o fator principal do desenvolvimento da profissão, em plano elevado". Ao saudar os presentes, em nome da Associação Brasileira de Enfermeiras Diplomadas, peço às enfermeiras Que tenham em mente os fatos e os princípios assinalados ${ }^{(6)}$. 
Contar a trajetória dos Congresso de Enfermagem é como percorrer uma estrada Que lentamente se constrói e vai delineando o contorno e o relevo desta entidade. Assim sendo, o primeiro momento deste relato serve para inserir o leitor no mundo não tão neutro no Qual surgiu a enfermagem brasileira; mundo revestido de subjetividades, construído com muita luta, mas também com certos benefícios do Estado ${ }^{(7)}$. É certo Que as pioneiras da ABEn precisavam consolidar a profissão e, apesar de suas diferentes visões e projetos, não puderam fugir de uma aliança Que alimentou lutas comuns em torno de um papel da enfermagem na sociedade.

No interior desta aliança e como uma de suas bandeiras, o CBEn passa a ocupar "o espaço de expressão da Enfermagem Brasileira"(8). $E$ isto pode ser valorizado como parte de um legado de um grupo de pioneiras Que empreenderam a conformação da identidade da enfermeira no Brasil: "o legado histórico das pioneiras da enfermagem no Brasil é a herança Que QualQuer grupo humano pode almejar de seus antepassados"(9).

A partir de 1947 O Congresso foi realizado no prédio inacabado da Escola de Enfermagem da USP. A presidente nessa época era Marina Bandeira de Oliveira (abril de 1947 a julho de 1948) ${ }^{(4)}$.

O CBEn se tornou atividade regular da ABEn, sendo realizado anualmente em uma capital do país. Somente não ocorreu no ano de 1953, Quando a ABEn hospedou o X Congresso Quadrienal do ICN em Petrópolis e, em 1961, Quando ocorreu no Rio de Janeiro o Congresso do Comitê Internacional Católico de Enfermeiros e Assistentes Médicos Sociais (CICIAMS).

O IV Congresso Nacional de Enfermagem (CNE) realizado na Bahia foi o primeiro a contar com um regimento e muitas participantes estrangeiras, com destaque para as representantes do Conselho Internacional de Enfermeiras ${ }^{(4)}$. Neste momento se discutia a criação da Federação Interamericana de Enfermagem, tema recorrente em encontros Internacionais Que reuniam latinoamericanas, pois tal organização era de "grande interesse para Que as enfermeiras americanas pudessem ocupar melhores posições no Conselho Internacional de Enfermeiras", uma vez Que seria uma forma de controle sobre as enfermeiras desta região do mundo ${ }^{(10)}$; ao mesmo tempo em Que a adesão das latino-americanas poderia fortalecer as enfermeiras norte-americanas no ICN. Entre 1947 e 1955, portanto do primeiro ao oitavo, chamou-se Congresso Nacional,a partir do nono, em 1956,Congresso Brasileiro, denominação atual.

Do primeiro Congresso, pensado como meio de reunir as enfermeiras, reservando o turno da manhã para passeios e a tarde para reuniões, até os congressos mais recentes, o CBEn desenvolveu e aprimorou novos valores, trazendo para dentro do evento toda a realidade Que se apresentava no dia-a-dia das enfermeiras. Assim sendo, gradativamente o CBEn vai incorporando toda a programação da ABEn, como as reuniões de diretoria, as Assembléias de Delegados, os encontros de seções da ABEn, em paralelo ou concomitante com as atividades do conclave, inclusive por medidas econômicas. Em 1967, após o XIX CBEn, Clarice Ferrarini sugeriu Que durante os próximos congressos fossem realizados cursos de atualização pré-congresso, o Que foi aprovado a partir de $1968^{(4)}$. Esta prática, Que se mantém ate hoje, cria uma agenda Que serve para dar visibilidade a enfermagem local e tem grande freqüência de estudantes.

O CBEn é o mais competente instrumento criado pela ABEn para passar sua mensagem aos sócios, ainda Que não seja o único. Mas neste é possível perceber a presença do pensamento da diretoria Que está no comando. Inicialmente a ABEn indicava pessoas, em geral de São Paulo, Rio de Janeiro ou da Bahia, para a composição da Comissão de Temas. Desde a ascensão do Movimento Participação ao comando da ABEn (1986), a Diretoria passou a delegar a organização do CBEn à seção Que vai sediá-lo. Apesar de uma relativa autonomia da seção com relação ao temário, a programação do evento deve ser aprovada em CONABEn (Conselho Nacional da ABEn) e na sua fase de construção as comissões devem aceitar sugestões da Diretoria Nacional, inclusive indicação de palestrantes $^{(11)}$.

A necessidade de divulgação do discurso oficial da Enfermagem brasileira se alia aos requisitos acadêmico-científicos de publicação e vão produzir uma nova demanda - a de publicar os resultados do evento, na íntegra, na forma de anais. Isto acontece a partir de 1977, expandindo a capacidade de retratar o mais amplamente possível tais produtos, uma vez Que, até então, a divulgação destes se dava de modo muito mais sintético, por meio da Revista Brasileira de Enfermagem (REBEn). Na verdade, deste modo também se aumentava o espaço para outras publicações no periódico, o Que se supõe já fosse uma reivindicação da comunidade científica.

De 1977 a 2006, só não foram editados os anais referentes aos Congressos de 1986, 1988, e 2006. Os congressos acontecem no ultimo Quadrimestre do ano e a publicação dos anais ocorre no ano seguinte, com exceção dos anos de 1977, 1987 e 2004 (publicados no mesmo ano), 1991 (publicado apenas em 1998), 1992 (publicado apenas em 1997) e 2005 ( publicado em 2007). Num processo de decisão bastante polêmico, no ano de 2001 foi incorporada a edição do livro programa/resumos em CD-ROM, o Que abriu espaço para a aprovação da edição dos anais neste mesmo suporte (meio digital), o Que já era anterior solicitação de seções organizadoras do evento. Já em 1977 os Anais foram indexados com ISSN (indexação própria para publicações periódicas) e, em 2002 passam a receber indexação com ISBN (indexação para livros), se adeQuando ao modelo de registro da produção científica dentro da Plataforma Lattes do CNPQ, Ou seja, esta plataforma só aceita registro de produção em anais com ISBN, apesar de a indexação como publicação periódica ser, talvez, a mais pertinente e interessante neste caso, porque existe uma continuidade do evento.

O 56 $6^{\circ}$ CBEn realizado em Gramado em 2004, foi o primeiro evento a distribuir os anais em forma de publicação virtual, patrimoniado no sítio de Internet da ABEn. Além disso, suas inscrições foram totalmente informatizadas, modelo logo seguido pelos outros organizadores de eventos na ABEn e, Que está perfeitamente integrado à política da Associação.

\section{Os congressos como Arena Política da Enfermagem}

Os congressos se constituem em espaços políticos privilegiados, pois reúnem profissionais de todo o país, Que participam e discutem o tema do evento, sempre relacionado ao contexto da profissão. Possibilitam um intercâmbio técnico, político e cultural entre profissionais, Que dificilmente seria viável em outro cenário. Suas recomendações se concretizam em inúmeras realizações da enfermagem brasileira. Ora organiza seus temas decompondo um tema geral, ora constrói o tema durante as discussões; em ambas as situações produzem documentos com a finalidade de dar 
encaminhamento às Questões Que afetam a profissão e Que foram deliberadas em suas plenárias.

Especialmente a partir da década de 80 o evento desenvolve temas relacionados com a conjuntura, como defendiam os novos dirigentes da $\mathrm{ABEn}$, trazendo para dentro do Congresso o contexto em Que estava acontecendo a prática de enfermagem. Procura fazer com Que os exercentes de enfermagem participem com outros agentes da sociedade das Questões emergentes na área da saúde e se aliem aos outros movimentos sociais, como parte da sociedade civil $^{(12)}$.

Desde 1987, os congressos da ABEn delinearam um novo perfil, ampliando seus objetivos. Além do espaço de aprimoramento dos conhecimentos técnico-científico passaram a assumir o papel de um fórum de reflexão, discussão e decisão das grandes Questões políticas, econômicas e sociais Que afetam a sociedade e os trabalhadores brasileiros"(13)

Esta nova feição do CBEn se deve a um processo bem mais complexo de transformações, Que passou a ser conhecido como o Movimento Participação. Este teve suas origens em Santa Catarina, entre os jovens líderes Que despontavam nesse estado, no final da década de $70^{(14)}$. Surge em meio a um panorama de crise de representatividade e liderança no interior da ABEn, Que conformou uma ruptura política de crítica e renovação. Sua primeira grande manifestação ocorre no ano de 1979 no XXXI Congresso Brasileiro de Enfermagem na cidade de Fortaleza e, a partir de então, toma corpo e presença mais fortalecida a cada CBEn. Em 1984, esses atores se organizam para concorrer às eleições gerais da Associação. Não é nesse momento Que ingressam na Entidade, pois a anulação parcial das eleições resultou na derrota do novo grupo, liderado pelos integrantes do MP. Mas conseguem desestabilizar o comando da ABEn, se rebelando contra a forma como esta era conduzida. Para tanto, constituíram diretorias provisórias nos estados em Que as eleições foram invalidadas, estratégia em Que restringiram o envio de dinheiro para a direção central do órgão, fator Que foi fundamental na negociação dos dois grupos para acelerar o processo de implementação de uma política democrática no cerne da organização. Assim, no início de 1986 houve negociação do grupo Que estava no comando com membros da diretoria provisória, sendo acordada a redução do mandato da diretoria e a antecipação das eleições gerais, além de uma reforma geral no estatuto da entidade.

Tal reforma apresentava Questões de fundo muito significativas, como a de implementar o ingresso dos estudantes como sócios da entidade, algo até então visto com muitas restrições pelas lideranças da ABEn; e a criação de uma instância em Que estivesse representada cada uma das seções, Que resultou na criação do Conselho Nacional da ABEn (CONABEn). A tomada do poder pelas lideranças oriundas do MP ocorre por meio das eleições de 1986 e, a partir de então, assumem uma forma diferente de administrar a ABEn. Os Congressos serão agora um espaço político ampliado, Que simboliza no mote "participação" o desejo de uma nova expressão profissional, para a Qual "as/os enfermeiras/os são chamadas/os a olhar para fora de si, sair da clausura, buscar uma nova maneira de pensar, e principalmente, Questionar sempre em busca de novas soluções para problemas antigos"(1)

Sem dúvida, há muitas formas de analisar as temáticas dos CBEns, categorizando eixos e relacionado-os com acontecimentos e interesses na cena histórica. No presente estudo parte-se do pressuposto do CBEn como um estratégia privilegiada da $\mathrm{ABEn}$ para atingir seus fins, portanto, é de se considerar que a forma de propor pautas e operacionalizar sua ampla divulgação é reveladora da conformação desta arena política, embora algumas poucas facetas possam aQui ser exploradas.

Muito além de uma simples análise temática, o Que este acervo histórico nos desafia a compreender é o cenário que se desenrola e dá significado à cena principal. Os bastidores e todo o conjunto de atores e atos Que criam, armam as condições a partir das Quais emerge um tema eleito, esta é a riqueza Que merece vir à tona neste tipo de olhar. $\mathrm{O}$ Quadro I, sintetiza informações Que podem motivar muitos outros olhares. Neste texto, destacamos alguns exercícios de análise, exemplares da produtividade deste material como fonte de estudo para a enfermagem.

A intenção de dar visibilidade à sua própria agenda por meio do CBEn parece ser uma tônica permanente na ABEn, apesar de tudo Que possa caracterizar mudança ou continuidade desta agenda ou de suas vinculações político-ideológicas. Como exemplo, podemos recorrer a eleição do tema do IX CBEn, em Porto Alegre em 1956, "Ética e Ensino Clínico", justamente no período em Que a Associação discutia seu código de ética ${ }^{(16)}$. Ou os temas do XVI CBEn, ocorrido em Salvador em 1964, Que em plena ditadura discutiu "Pesquisa em Enfermagem e Enfermagem: Profissão Liberal". Neste momento o Ministério do Trabalho havia emitido portaria classificando a profissão de enfermeiro na categoria de profissão liberal, feito Que gerou muitas defesas e divulgação na Revista Brasileira de Enfermagem, por ser considerado um motivo de orgulho para a profissão. Era o momento de dar ao acontecimento o mérito de uma conquista Que validava o discurso e o empenho da ABEn como representante da categoria de enfermagem no Brasil. Além disso, o tema que abordava pesQuisa, pela primeira vez aparecia nos CBEn, ao que parece como resultado do Levantamento de Necessidades e Recursos de Enfermagem, projeto cujo efeito simbólico de seus resultados tiveram impacto internacional na visibilidade da Associação ${ }^{(17)}$.

Se, em alguns momentos a intenção se dirigia para a reafirmação do papel propositivo da entidade na luta pelos ideais e objetivos profissionais - sejam do plano educacional, assistencial ou organizativo, entre outros Que podem ser vislumbrados na coluna do tema oficial - em outros momentos tal intenção se voltava para capturar os movimentos e as perspectivas de futuro Que se delineavam no contexto do trabalho em saúde. Assim, por exemplo, a agenda política no campo da saúde era o foco da atenção, como no CBEn de 1981, em Manaus, no Qual o tema "Saúde para todos" se alinhava as recentes proposições da Conferência Alma-ATA (1978) e suas implicações para o marco da Atenção Primária de Saúde e nas políticas públicas em saúde.

O tema da educação é um dos mais recorrentes ao longo da história dos CBEns. Desde sua terceira edição, em 1949 no Rio de Janeiro, já se colocava a discussão sobre o ensino de Pós-graduação, juntamente com o tema da regulamentação da Lei 775/1949 (primeira Lei do Ensino de Enfermagem no Brasil) e do Currículo para as escolas. Esta preocupação não perde sua centralidade em anos posteriores, como se mostra nos temas: "A fiscalização e reconhecimento de escolas" (1950); "Problemas relativos às escolas" (1951); "Currículos de escolas de Enfermagem" (1952); "Recrutamento e seleção para cursos de enfermagem" (1954); 


\begin{tabular}{|c|c|c|c|}
\hline CBEn & Data & Inscritos & Tema Central/oficial \\
\hline I & SP/ 1947 & 211 & Enfermagem de saúde pública, preparo de enfermeiras chefes, Enfermagem psiquiátrica \\
\hline II & $\mathrm{RJ} / \mathrm{l} 948$ & $32 \mathrm{I}$ & Organização sanitária, Enfermagem de saúde pública no Brasil, cursos de pós-graduação \\
\hline III & $\mathrm{RJ} / \mathrm{I} 949$ & $\mathrm{~N}$ & $\begin{array}{l}\text { Organização material de Enfermagem, Regulamentação da lei } 77 / 49 \text {, Enfermagem de saúde pública, } \\
\text { currículo para as escolas de Enfermagem }\end{array}$ \\
\hline IV & $\mathrm{Ba} / 1950$ & 295 & $\begin{array}{l}\text { Enfermagem profissional, especialidades em Enfermagem, o programa do ponto IV,o auxiliar de } \\
\text { enfermagem, fiscalização para o reconhecimento de escolas de Enfermagem }\end{array}$ \\
\hline V & $\mathrm{RJ} / \mathrm{I} 95 \mathrm{I}$ & 504 & $\begin{array}{l}\text { Problemas relativos às escolas de Enfermagem, problemas relativos à Enfermagem hospitalar, Problemas } \\
\text { relativos à Enfermagem de saúde pública }\end{array}$ \\
\hline $\mathrm{VI}$ & SP/1952 & 517 & Currículo de escola de Enfermagem, obstetrícia, supervisão \\
\hline VII & SP/1954 & 577 & $\begin{array}{l}\text { Recrutamento seleção para cursos de Enfermagem e auxiliar e Enfermagem, Departamento de Enfermagem } \\
\text { no hospital moderno }\end{array}$ \\
\hline VIII & $\mathrm{BH} / 1955$ & $4 I I$ & O papel da Enfermagem no programa de assistência médico/hospitalar \\
\hline IX & PoA/I 956 & 417 & Ética, Ensino clínico \\
\hline $\mathrm{X}$ & Niterói / 1957 & $\mathrm{~N}$ & A Enfermagem e a assistência à maternidade e à infância \\
\hline $\mathrm{XI}$ & Recife/1958 & 519 & Educação em serviço e temas livre \\
\hline XII & SP/1959 & 506 & $\begin{array}{l}\text { Discussão: como poderão os hospitais e as unidades sanitárias do Brasil dar melhor assistência de } \\
\text { Enfermagem ao público,Organização das escolas de Enfermagem e de auxiliares de Enfermagem }\end{array}$ \\
\hline XIII & $\mathrm{BH} / \mathrm{I} 960$ & 484 & Sindicalismo, temas livre \\
\hline XIV & Curitiba/l 962 & 489 & Enfermagem Hospitalar, Enfermagem de Saúde Pública \\
\hline $\mathrm{XV}$ & Fortaleza/1963 & 483 & Saúde pública no nordeste, temas livre \\
\hline XVI & Salvador/I 964 & 613 & Enfermagem e pesquisa, assistência de Enfermagem, Enfermagem: profissão liberal, temas livre \\
\hline XVII & $\mathrm{RJ} / 1965$ & 1542 & Enfermagem na realidade brasileira, temas livre \\
\hline XVIII & Belém/I 966 & $\mathrm{~N}$ & Serviço de Enfermagem \\
\hline XIX & Brasília/ 1967 & $\mathrm{~N}$ & $\begin{array}{l}\text { Tendências na formação da Enfermeira, Enfermagem na evolução hospitalar, Pesquisa e Enfermagem, } \\
\text { Enfermagem no processo de desenvolvimento sócio-econômico. }\end{array}$ \\
\hline $\mathrm{XX}$ & Recife/ 1968 & $\mathrm{~N}$ & A enfermeira em uma sociedade em desenvolvimento \\
\hline XXI & PoA/I969 & 1137 & Comunicação: elemento essencial para o desenvolvimento da Enfermagem \\
\hline XXII & SP/1970 & 1016 & $\begin{array}{l}\text { Integração dos recém-graduados a vida profissional, Política da ABEn,Elementos básicos do diagnóstico de } \\
\text { enfermagem, Temas livres }\end{array}$ \\
\hline XXIII & Manaus/197I & 661 & $\begin{array}{l}\text { Princípio de investigação e processo de observação sistematizada da enfermagem, O papel da enfermeira } \\
\text { nos serviços de saúde diante da realidade regional do Brasil, Participaçãa da enfermeira no planejamento } \\
\text { de saúde, Recentes estudos e pesquisas nas especialidade de enfermagem, Temas livres. }\end{array}$ \\
\hline XXIV & $\mathrm{BH} / \mathrm{I} 972$ & 1051 & $\begin{array}{l}\text { Formação dos profissionais de enfermagem dos três níveis,Exercício profissional, O enfermeiro e a } \\
\text { comunidade, Recentes pesquisas em enfermagem, Temas livres. }\end{array}$ \\
\hline $\mathrm{XXV}$ & João P/I973 & 969 & $\begin{array}{l}\text { O currículo mínimo do curso de graduação em Enfermagem; Recentes pesquisas em enfermagem; } \\
\text { Problemas relacionados com o ensino e o exercício da enfermagem nas áreas: médico-cirúrgica, materno- } \\
\text { infantil, de administração de saúde pública, Humanização da enfermagem. }\end{array}$ \\
\hline $\mathrm{XXVI}$ & Curitiba/I 974 & 1003 & $\begin{array}{l}\text { Necessidades psico-sociais e psico-esperituais dos pacientes, Liderança; } \\
\text { Recentes pesquisas em enfermagem, Aspectos assistenciais da enfermagem, Problemas de infecção } \\
\text { hospitalar. }\end{array}$ \\
\hline XXVII & Salvador/1975 & 1779 & $\begin{array}{l}\text { Integração do ensino de enfermagem, Participação do pessoal de enfermagem nos programas de } \\
\text { assistência à saúde nas populações da zona rural, Problemas de assistência de enfermagem em hospitais e } \\
\text { clínicas particulares de grandes centros urbanos, Recentes pesquisas em enfermagem, Temas livres. }\end{array}$ \\
\hline XXVIII & $\mathrm{RJ} / \mathrm{l} 976$ & 2438 & $\begin{array}{l}\text { Formação filosófica e religiosa de enfermeiras; Sistema de registro de enfermagem; Projeção da ABEn na } \\
\text { comunidade brasileira;Pesquisas em enfermagem, Temas livres }\end{array}$ \\
\hline XXIX & Camboriu/1977 & 1639 & $\begin{array}{l}\text { Situação da saúde no país - implicações para a prática de enfermagem, } \\
\text { Relações de enfermagem com as demais carreiras universitárias, } \\
\text { Licenciatura em enfermagem, Temas livres. }\end{array}$ \\
\hline $\mathrm{XXX}$ & Belém/I 978 & 1414 & $\begin{array}{l}\text { A enfermagem e o sistema nacional de saúde, } \mathrm{O} \text { ensino e a assistência de enfermagem face os programas } \\
\text { de extensão de cobertura de saúde, As inovações do ensino superior de enfermagem face à assistência da } \\
\text { saúde da população - possibilidades e limitações, As entidades de classe das Quais o enfermeiro participa, } \\
\text { Temas livres. }\end{array}$ \\
\hline $\mathrm{XXXI}$ & Fortaleza/1979 & 2499 & $\begin{array}{l}\text { A enfermagem e a estrutura social, Reflexões sobre a prática de enfermagem, Preparo e aperfeiçoamento } \\
\text { de recursos humanos para a enfermagem, Temas livres. }\end{array}$ \\
\hline XXXII & Brasília/ 1980 & 2167 & $\begin{array}{l}\text { A Previdência Social. A competência continuada e assistência de enfermagem, Relação de ajuda, Temas } \\
\text { livres }\end{array}$ \\
\hline XXXIII & Manaus/198I & 1163 & $\begin{array}{l}\text { "Saúde para todos", O enfermeiro e a enfermagem, A enfermagem e os serviços básicos de saúde, A } \\
\text { enfermagem e a tecnologia apropriada: adeQuação da prática à realidade brasileira }\end{array}$ \\
\hline XXXIV & POA/I982 & 2288 & Saúde e Educação \\
\hline XXXV & SP/I983 & 3300 & O que a Enfermagem pode fazer por você e pelo Brasil \\
\hline XXXVI & $\mathrm{B} \mathrm{H} / \mathrm{I984}$ & 2700 & Trabalho e saúde: desafios para a Enfermagem \\
\hline
\end{tabular}

Quadro 1. Congressos Brasileiros de Enfermagem no período de 1947 a 2006 . Fonte: Mancia ${ }^{(15)}$. 


\begin{tabular}{|c|c|c|c|}
\hline CBEn & Data & Inscritos & Tema Centra/oficial \\
\hline XXXVII & Recife/ 1985 & 4232 & Tendências da prestação de serviços de saúde no país e a prática da Enfermagem \\
\hline XXXVIII & $\mathrm{RJ} / \mathrm{I} 986$ & 5882 & Os 60 anos da ABEn e a Enfermagem brasileira \\
\hline XXXIX & Salvador/1987 & 4000 & Trabalho na Enfermagem \\
\hline $\mathrm{XL}$ & Belém/1988 & 1647 & A força do trabalho na Enfermagem \\
\hline 41 & Fpolis/1989 & 3594 & Os desafios da Enfermagem para os anos 90 \\
\hline 42 & Natal// 990 & 4000 & A construção de uma nova prática \\
\hline 43 & Curitiba/I991 & 2160 & Assistência de Enfermagem \\
\hline 44 & Brasília/I992 & 1558 & Enfermagem: luta pela vida \\
\hline 45 & Recife/I993 & 2870 & A Enfermagem numa perspectiva de saúde com Qualidade \\
\hline 46 & PoA/1994 & 3146 & Enfermagem compromisso com a vida \\
\hline 47 & Goiânia/l995 & 2681 & O poder (in)visível da Enfermagem \\
\hline 48 & SP/1996 & 3191 & Os 70 anos da ABEn e a Enfermagem brasileira \\
\hline 49 & B.H/1997 & 2008 & A Enfermagem os caminhos da liberdade \\
\hline 50 & Salvador/1998 & 3064 & Cuidar - ação terapêutica da Enfermagem \\
\hline 51 & Fpolis/1999 & 4176 & Enfermagem no mundo \\
\hline 52 & Recife/2000 & 3802 & Enfermagem 2000: crescendo na diversidade \\
\hline 53 & Curitiba/200l & 5831 & A concretude política e social da enfermagem \\
\hline 54 & Fortaleza/2002 & 5.835 & A Enfermagem, a ciência, a arte, a ética e a estética \\
\hline 55 & $\mathrm{RJ} / 2003$ & 4.168 & A vida com justiça social \\
\hline 56 & Gramado 2004 & 4.234 & Enfermagem hoje: coragem de experimentar muitos modos de ser \\
\hline 57 & Goiânia/ 2005 & 2863 & A Enfermagem na construção de um mundo solidário \\
\hline 58 & Salvador 2006 & 4.829 & Cuidado de Enfermagem: autonomia e regulação do trabalho em saúde \\
\hline 59 & Brasília/2007 & 1429 & A integralidade e a enfermagem na competência coletiva do cuidar em saúde \\
\hline
\end{tabular}

"Ensino clínico" (1956); "Organização das escolas de Enfermagem e de auxiliares de Enfermagem" (1959). Esta eleição é a tal ponto recorrente Que é pertinente considerar o CBEn foi, também, uma extensão das Reuniões de Escolas Que a Divisão de Educação da ABEn desenvolvia desde $194 I^{(18)}$.

A reflexão sobre o trabalho da enfermagem também adQuire nuances diferenciadas nos CBEns e poderia, por si só, produzir uma análise especifica. É certo Que o "trabalho" encontra-se explicita ou implicitamente retratado nas temáticas do evento, Quando esta se volta para campos específicos da atuação profissional, como a saúde pública (1947, 1949, 195 I 1963), as especialidades de enfermagem (1950), a enfermagem hospitalar (1951, 1954, 1955, 1962, 1967), entre outros. Mas um contraste de abordagem se estabelece a partir de 1984, Quando o XXXVI CBEn em Belo Horizonte, traz o tema "Trabalho e saúde: desafios para a Enfermagem". Vale lembrar o clima de mudança em construção pelo Movimento Participação, além do processo de abertura política no país e a entrada em cena de um novo discurso, firmado por enfermeiras pós-graduadas Que buscaram nas ciências humanas e sociais novos aportes para a análise da enfermagem e da saúde no Brasil.

Mas, com certeza, foi o $41^{\circ} \mathrm{CBEn}$ (1989), em Florianópolis Que, com o tema central "Os desafios da enfermagem para os anos 90", levou para o debate o processo de trabalho da enfermagem. Os sub-temas trouxeram resultados de estudos especialmente desenvolvidos para o evento(19,20) e Que identificaram nos discursos da categoria diferentes objetos de trabalho (- o corpo individual; - a organização da assistência; - a consciência dos indivíduos sobre saúde) e instrumentos de trabalho (- para viabilizar o cuidado; - para possibilitar o processo administrativo; - para a educação em saúde; - para a produção de conhecimentos). No sub-tema "Os desafios da enfermagem para os anos 90" foram reconhecidas as possíveis direções da enfermagem para os anos
90 e desafio de "Compreender o trabalho da enfermagem no conjunto das Práticas sociais e, internamente, nos seus diferentes momentos", considerado como base e pré-condição para o encaminhamento de um segundo desafio, o de "construir um projeto político para a enfermagem no sentido da realização de seu trabalho, de modo Que alcance a valorização e resolutividade desejadas"(20). Outro marco deste evento foi a análise do processo de trabalho em enfermagem no modelo de saúde individual e coletiva, salientando Que o processo de trabalho de enfermagem em saúde coletiva está em construção e necessita, para sua organização tecnológica, recriar modelos de processo de trabalho Que contemplem objetos e finalidades coletivas ${ }^{(21)}$. Dez anos depois, em 1999, a seção Santa Catarina novamente trará a discussão política sobre o trabalho da Enfermagem, desta vez no cenário nacional e internacional, ao eleger o tema "Enfermagem no mundo". Neste momento de expectativa e avaliação, às portas de um novo milênio, em uma mesa especifica na programação do evento já se pôde lançar um olhar retrospectivo sobre o Que a enfermagem brasileira produziu na linha de pesquisa do processo de trabalho em saúde e enfermagem,

Existem estudos que utilizaram os CBEns e seus anais como fonte de dados para a compreensão das perspectivas e tendências profissionais, sob diferentes ângulos de abordagem. O primeiro deles, "33 Congressos Brasileiros de Enfermagem" foi um livro lançado em 1982, Que traz informações de todos os Congressos desde 1947 a $1981^{(22)}$. Essa produção tem uma importância ímpar, porQue foi a primeira publicação Que abordou todos os Congressos. No entanto, seu lançamento não foi valorizado pelas dirigentes da entidade, Que não lhe deram a visibilidade devida, naquela ocasião, o Que nos perece contribuiu para Que esse livro, ainda hoje seja pouco conhecido.

No ano de 2000 a ABEn lança o livro "Congressos Brasileiros de Enfermagem - meio século de compromisso da ABEn" Que se 
refere à recuperação histórica do contexto social e análise dos temas do evento e 1947 a $1997^{(23)}$.

Em 2002, Mancia ${ }^{(1)}$ desenvolve sua dissertação de mestrado em torno do tema: A ABEn-RS e as enfermeiras assistenciais - uma análise reflexiva. $\mathrm{Na}$ Qual utiliza o Congresso como categoria de análise, fazendo um resgate da trajetória do evento.

Na tese "Revista Brasileira de Enfermagem e seu papel na consolidação profissional" ${ }^{(15)}$, defendida em 2007, o autor traça a trajetória da ABEn e da profissão por meio da Revista, órgão oficial de divulgação da Associação.

Padilha, Silva e Borenstein ${ }^{(1)}$, em estudo relativo as convergências presentes nos discursos dos Congressos Brasileiros de Enfermagem no período de 1977 a 1987 detectaram Quatro pontos centrais nas discussões dos Congressos e que vinham ao encontro das políticas de saúde e educação brasileiras. Sao eles: Educação Superior, Assistência de Enfermagem nas instituições de saúde, Política de Saúde e a Imagem da/o Enfermeira/o. Além de pontuar os principais acontecimentos políticos e tecnológicos Que fundamentavam as escolhas temáticas dos Congressos, como mudanças na legislação do ensino, a consolidação da pós-graduação e da pesquisa em enfermagem, a reforma sanitária e o SUS, entre outros; as autoras também analisaram o conteúdo dos Anais dos CBEns no período de 1977 a 1987 em relação a um perfil Quanto a configuração Quantitativa de mesas de temas oficiais, palestrantes e dabatedores.

O CBEn é o maior evento de enfermagem do Brasil. Tem uma longa vida, está em sua $60^{\text {a }}$ edição e muito vigoroso. O seu crescimento em número de participantes preocupava a $\mathrm{ABEn}$, portanto, alguns eventos foram se desprendendo do CBEn e
adQuirindo vida própria, como por exemplo o SENADEn, Que saiu do congresso para se tornar um evento específico, deixando menos pesada a pauta das reuniões de escolas, Que acontece anualmente no CBEn. Dos encontros de especialidades hoje acontecem no CBEn somente as reuniões de articulação; os temas são discutidos em Congressos das próprias sociedades de especialistas. Ainda assim, hoje o CBEn incorpora cada vez mais atividades e é um fórum Que discute toda a vida da enfermagem brasileira, em todos os seu $\operatorname{aspectos}^{(15)}$.

Inicialmente planejado para ser realizado pelo menos a cada dois anos ${ }^{(4)}$, sempre permaneceu anual. Seu saldo final representa uma importante receita para a $A B E n$ e seções. No entanto, nem todas as seções realizaram o CBEn; somente 14 estados (Todos realizados nas capitais dos estados exceto: Balneário de Camboriú (SC) em 1977 e Gramado (RS) em 2004, já o organizaram, a maioria deles mais de uma vez. Em 2005, ano em se negociou o CBEn para 2007, na primeira reunião do Conselho Nacional da ABEn (CONABEn), Que discutiu essa pauta não houve estado Que se propusesse a sediá-lo ${ }^{(24)}$.

Um fato interessante e recorrente é o do grande número de estudantes no CBEn, já desde sua primeira edição em 1947, cujo percentual de estudantes era de $50 \%$. Se por um lado, isto nos faz pensar Que essa problemática já estava presente nos primórdios do evento, de outro, precisamos considerar algumas particularidades, como o local em Que foi realizada o CBEn, a Escola de Enfermagem da USP, e principalmente o número de escolas existentes na época.

Interessante ressaltar o crescimento do número de estudantes Que participam do CBEn a partir de 2001, ano em Que ultrapassam o número absoluto de enfermeiras inscritas ( durante as décadas de

\section{EDITH DE MAGALHÃES FRAENKEL}

Destina-se ao melhor trabalho sobre Pesquisa de Enfermagem.

\section{ZAIRA CINTRA VIDAL}

Destina-se ao melhor trabalho sobre invenções, descobertas ou adaptações significativas para a prática de enfermagem.

\section{GLETE DE ALCÂNTARA}

Destina-se ao melhor trabalho CBEn sobre o Tema Central da Semana Brasileira de Enfermagem

\section{ZAURA BARBOSA LIMA}

Destina-se ao melhor trabalho sobre saúde pública

\section{LAÍS NETO DOS REIS}

Destina-se ao melhor trabalho sobre prática profissional Que represente uma expansão do papel do enfermeiro, porém com maior autonomia.

\section{NORACI PEDROSA MOREIRA}

Destina-se ao melhor trabalho sobre o tema central do CBEn do ano em curso.

\section{MARINA DE ANDRADE REZENDE}

Destina-se ao melhor trabalho sobre Enfermagem.

\section{IANE DA FONSECA PROENÇA}

Destina-se ao melhor trabalho sobre Enfermagem Psiquiátrica, Saúde Mental e Relacionamento Interpessoal

\section{WANDA DE AGUIAR HORTA}

Destina-se ao melhor trabalho sobre Prática de Enfermagem.

\section{MARCOS OTÁVIO VALADÃO E EDMA}

Destina-se ao melhor trabalho sobre lutas éticas e políticas da enfermagem.

\section{ROSI MARIA KOCH}

Destina-se melhor trabalho sobre Fundamentos de Enfermagem

IEPE

Destina-se a trabalhos sobre a Educação Permanente no contexto da Rede IEPE.

\section{ESCOLA DE ENFERMAGEM ALFREDO PINTO}

Destina-se ao melhor trabalho sobre História da Enfermagem Brasileira.

\section{HAYDÉE GUANAIS DOURADO}

Destina-se ao melhor trabalho sobre a ABEn: "Promoção do

Desenvolvimento Técnico, Científico, Cultural e Político dos Profissionais de Enfermagem".

VILMADE CARVALHO

Destina-se ao melhor trabalho sobre ensino de enfermagem.

Quadro 2. Relação dos Prêmios oferecidos no CBEn e justificativas. 
50 até 90 , essa participação estudantil não foi além de 30\%). É um indicativo de Que a diretoria da ABEn, mentora do Congresso, deva levar em consideração esse crescimento para a organização dos próximos eventos. Tal incremento tem reflexos importantes no saldo financeiro do CBEn, já Que os estudantes têm inscrições com valores significativamente mais baixos Que os profissionais já formados. Além disso, o Quadro permanente de sócios da ABEn também sofre forte interferência desse novo perfil do participante dos eventos da entidade, uma vez Que para se inscrever em eventos é necessário ser sócio da entidade.

Este novo cenário, onde os estudantes aparecem com a maior representatividade, precisa ser melhor considerado pela ABEn na concepção do evento e na sua programação final. Parece-nos Que até hoje temos organizado um evento com vistas a atender as necessidades dos enfermeiros. Entretanto, a participação dos estudantes no CBEn não tem garantido a vinculação destes como sócio da entidade. É um movimento Que não se expressa em outros momentos ou espaços da ABEn. A sessão de premiação, por exemplo, na Qual existem três prêmios para trabalhos de acadêmicos, ainda é pouco disputada, chegando a inexistência de concorrentes, o Que permite Questionar sobre os motivos desta não participação ${ }^{(24)}$.

Os estudantes, passaram a fazer parte do Quadro de sócios da ABEn somente a partir de 1986, com a implantação de um novo estatuto aprovado no início deste ano. A inclusão dos estudantes foi uma reivindicação de longa data, inclusive sua discussão suscitava medo nas dirigentes, como podemos constatar no seguinte excerto, do discurso de transmissão de cargo de uma ex- presidente "Eu faço votos à atual presidente da ABEn [...] de Que os estudantes acorram em número cada vez maior à Associação" (25), desejo Que expressava uma ameaça para a nova presidente. A participação dos estudantes nessa época era alguma coisa de inconveniente para a entidade.

Durante o Congresso, os trabalhos apresentados podem concorrer a prêmios instituídos a partir da década 50, sendo o primeiro criado em 1957 (Prêmio Edith de Magalhães Fraenkel, patrocinado pelos Laboratórios Crinas Sedas. Se constituía de uma medalha de prata dourada entregue ao melhor trabalho inédito apresentado por enfermeira sobre Centro Cirúrgico. Atualmente é patrocinado pela Escola de Enfermagem da USP(26), até um total atual de 15 premiações. Todavia, as premiações foram se adeQuando ao tempo e aos patrocinadores. De modo, Que alguns prêmios tiveram vida efêmera, posto Que estavam ligados a situações muito pontuais em dados momentos. Como o prêmio de Maria Rosa Souza Pinheiro instituído pelo Conselho Federal de Enfermagem, Que deveria estar premiando o melhor trabalho de estudante de enfermagem Que abordasse o tema do próprio COFEN. Tal prêmio, embora tenha o nome de uma eminente figura da ABEn, Que foi presidente da entidade por dois mandatos e, primeira presidente do referido Conselho, está suspenso até Que se resolvam as Questões Que deram origem a suspensão o prêmio.
No ano de 2007 foi criado um prêmio para melhor trabalho Que abordasse os 80 anos da ABEn. Criado para este fim específico. Assim, em outros momentos foram criados prêmios para dar visibilidade a determinados temas de interesse da ABEn. Assim sendo, atualmente a ABEn distribui 15 prêmios, como demonstrado no Quadro abaixo. Alguns deles criados recentemente, como o prêmio Haydée Guanais Dourado apresentado na AND do $58^{\circ}$ CBEn em Salvador, em novembro de 2006. Outros, como o prêmio Marcos e Edma, surgiu em momento de profunda comoção na entidade, pelo assassinato destes sócios, profissionais Que estavam envolvidos com projeto de defesa da profissão. E se constituem hoje em um princípio da categoria, Que deseja ver esclarecidos os assassinatos e punidos seus culpados. Outros prêmios são exclusivamente para estudantes de graduação como : Marina de Andrade de Rezende, Glete de Alcântara e Escola de Enfermagem Alfredo Pinto. Do total dos 15 prêmios disponíveis no CBEn de 2006 não houve premiação em 5 títulos.

\section{CONSIDERAÇÕES FINAIS}

Ao retratar os limites e, ao mesmo tempo, as possibilidades e a abrangência da ação profissional, os Congressos Brasileiros de Enfermagem, apontaram novos caminhos para a construção do conhecimento em enfermagem, os Quais se consubstanciariam em novos paradigmas para a profissão, no sentido de torná-la mais crítica, participativa e comprometida com as Questões sociais, políticas e econômicas, Que determinam as políticas de educação e saúde ${ }^{(27)}$.

Nesta perspectiva, os Congressos Brasileiros de Enfermagem, desde o seu inicio em 1947, refletiram a construção da história da Enfermagem brasileira da época, realizada por gerações de enfermeiras e enfermeiros, com vistas a impulsionar a reflexão crítica dos problemas da profissão e investir na produção de conhecimentos, direcionados para a crescente complexidade e Qualidade da prática profissional.

As categorias apontadas continuam a permear os discursos da Enfermagem o Que reflete o processo dinâmico e político no avanço deste conhecimento. Evidencia também Que as transformações no contexto da Enfermagem estão diretamente relacionadas às transformações mais globais, ou seja, à estrutura sócio-econômicopolítica do sistema como um todo.

Os CBEn se constituem no mais poderoso instrumento utilizado pela ABEn para transmitir sua ideologia. É através dele, principalmente, Que a ABEn consolida seu discurso sobre a enfermagem brasileira ${ }^{(I l)}$.

Finalizando diríamos que os Congressos Brasileiros de enfermagem acompanharam e lançaram novos paradigmas para a profissão, permitindo ao longo do tempo, Que esta se tornasse mais crítica e socialmente mais participativa e finalmente uma profissão comprometida efetivamente com a saúde da população e não mais simplesmente executora de políticas de saúde.

\section{REFERÊNCIAS}

I. Padilha MICS, Silva AL, Borenstein MS. Os congressos brasileiros - pontes para a liberdade e transformação da enfermagem. Rev Lat-am Enfermagem 2001;9(3): 7-13.
2. Padilha MICS, Borenstein MS. O método de pesquisa histórica na enfermagem. Texto Contexto Enferm 2005; I 4(4): 575-84. 
3. Secaf V, Costa HCBV. Enfermeiras do Brasil- história das pioneiras. São Paulo: Martinari; 2007.

4. Carvalho AC. Associação Brasileira de Enfermagem- 19261976, documentário. Brasília: ABEn; 1976.

5. Barreira IA, Sauthier I, Baptista SS. O movimento associativo das enfermeiras na primeira metade do século XX. Rev Bras Enferm 2001;54(2): 157-73.

6. Fraenkel EM. Saudação de Dona Edith Fraenkel, diretora da Escola de Enfermagem e presidente da Associação Brasileira de Enfermeiras Diplomadas, seção São Paulo. Anais Enferm 1947; 16 (22): 22.

7. Germano RM. A contribuição social da ABEn na Enfermagem Brasileira: uma perspectiva histórica. In: Anais do $48^{\circ}$. Congresso Brasileiro de Enfermagem; 1996 out 6-I I; São Paulo (SP), Brasil. São Paulo: ABEn; 1997. p. 147-69.

8. Mancia IR. Congresso Brasileiro de Enfermagem- espaço de expressão da enfermagem brasileira. Rev Bras Enferm 200I; 54(3): 397.

9. Lopes MGD. Discurso. In: Anais do $48^{\circ}$. Congresso Brasileiro de Enfermagem; 1996 out 6-I I; São Paulo (SP), Brasil. São Paulo: ABEn; 1997. p. 34-6.

10. Barreira IA, Baptista SS. Haydée Guanais Dourado: carisma e personalidade a serviço de um ideal. Rev Bras Enferm 2002; 55(3): 275-92.

I I. Mancia IR. A ABEn e as enfermeiras assistenciais: uma análise reflexiva [dissertação]. Florianópolis (SC): Departamento de Enfermagem, Universidade Federal de Santa Catarina; 2002.

12. Pires DEP. Discurso da presidente da comissão executiva do $41^{\circ}$ Congresso Brasileiro de Enfermagem-sessão de abertura. In: Anais do $41^{\circ}$. Congresso Brasileiro de Enfermagem; 1989 set 2-7; Florianópolis (SC), Brasil. Florianópolis: ABEn, 1989. p. 29-33.

13. Vale EG. Discurso de abertura do $52^{\circ}$ Congresso Brasileiro de Enfermagem- Presidente da ABEn- Nacional. In: Anais do $52^{\circ}$. Congresso Brasileiro de Enfermagem; 2000 out 2 1-26; RecifeOlinda (PE), Brasil. Recife (PE): ABEn; 200 I. p.12-6.

14. Albuquerque GL. O movimento participação na Associação Brasileira de Enfermagem- Seção Santa Catarina, na visão de suas principais lideranças [tese]. Florianópolis (SC): Departamento de Enfermagem, Universidade Federal de Santa Catarina; 200I .

15. Mancia JR. Revista Brasileira de Enfermagem e seu papel na consolidação profissional [tese]. Florianópolis (SC): Departamento de Enfermagem, Universidade Federal de Santa Catarina;2007.

16. Associação Brasileira de Enfermagem. Livro de Atas n.3 Reuniões de diretoria de 1955 a 1960. Rio de Janeiro: ABEn; 1960.

17. Associação Brasileira de Enfermagem. Livro de Atas n.4 Reuniões de diretoria de 1960 a 1964. Rio de Janeiro: ABEn; 1964.

18. Carvalho AC. Escola de Enfermagem da Universidade de São Paulo. Resumo histórico-1942-1980. Rev Esc Enferm USP 1980 ago; 14(supl): 1-271.

19. Almeida MCP, Rodrigues AM, Castellanos BEP, Rosa MTL, Mendes SASA. A situação da enfermagem nos anos 80. In: Anais do $41^{\circ}$ Congresso Brasileiro de Enfermagem; 1989 set 2-7; Florianópolis (SC), Brasil. Florianópolis: ABEn; 1989. p. 43-75.

20. Castellanos BEP, Rodrigues AM, Almeida MCP, Rosa MTL, Mendes SASA. Os desafios da enfermagem para os anos 90. In: Anais do $41^{\circ}$ Congresso Brasileiro de Enfermagem; 1989 set 2-7; Florianópolis (SC), Brasil. Florianópolis (SC): ABEn; 1989. p. 147-69.

21. Ramos FRS. O processo de trabalho de educação em saúde. In: Ramos FRS, Verdi MM, Kleba ME. Para Pensar o cotidiano: educação em saúde e a práxis de enfermagem. Florianópolis: EDUFSC; 1999.

22. Schmarczek M. 33 anos do Congresso Brasileiro de Enfermagem-retrospectiva. Porto Alegre: ABEn; 1982.

23. Fonseca RMS, Forcella HT, Bertolozzi MR, organizadoras. Congressos Brasileiros de Enfermagem: meio século de compromisso da ABEn. Brasília: ABEn; 2000.

24. Associação Brasileira de Enfermagem . Ata da $48^{a}$ Reunião do Conselho Nacional da ABEn-CONABEn. 30-31 out 2005. Goiânia: ABEn; 2005.

25. Castro, IB. Discurso de transmissão de cargo de presidente da ABEn proferido na sessão de encerramento do XXXII Congresso Brasileiro de Enfermagem. In: Anais do XXXII. Congresso Brasileiro de Enfermagem; 1980 jun I-7; Brasília (DF), Brasil. Brasília: ABEn; 1980. p.135.

26. Mancia IR, Padilha MICS. Trajetória de Edith Magalhães Fraenkel. Rev Bras Enferm 2006; 59 (esp): 432-7.

27. Silva AL, Padilha, MICS, Borenstein MS. Imagem e identidade profissional na construção do conhecimento em enfermagem. Rev Lat-Am Enfermagem 2002; 10(4): 586-95. 